\title{
Decitabine for Treatment of Myelodysplastic Syndromes in Chinese Patients: An Open-Label, Phase-3b Study
}

\author{
Depei Wu $\cdot$ Xin Du $\cdot$ Jie Jin $\cdot$ Zhijian Xiao $\cdot$ Zhixiang Shen $\cdot$ Zonghong Shao \\ Xiao Li $\cdot$ Xiaojun Huang $\cdot$ Ting Liu $\cdot \mathrm{Li} \mathrm{Yu} \cdot$ Jianyong Li $\cdot$ Baoan Chen · \\ Guangsheng He $\cdot$ Zhen Cai $\cdot$ Hongchuang Liang $\cdot$ Jigang Li $\cdot$ Changgeng Ruan
}

To view enhanced content go to www.advancesintherapy.com

Received: September 9, 2015 / Published online: November 14, 2015

(C) The Author(s) 2015. This article is published with open access at Springerlink.com

\begin{abstract}
Introduction: The objective of this study was to evaluate the efficacy and safety of decitabine in Chinese patients with myelodysplastic syndrome (MDS).
\end{abstract}

Methods: Patients ( $\geq 18$ years) who had a de novo or secondary MDS diagnosis according to

Electronic supplementary material The online version of this article (doi:10.1007/s12325-015-0263-8) contains supplementary material, which is available to authorized users.

D. Wu $\cdot$ G. He $\cdot$ C. Ruan $(\bowtie)$

The First Affiliated Hospital of Soochow University, Suzhou, Jiangsu, People's Republic of China

e-mail: changgengruan@hotmail.com

X. Du

Guangdong General Hospital, Guangzhou,

People's Republic of China

J. Jin · Z. Cai

The First Affiliated Hospital, Zhejiang University

College of Medicine, Hangzhou, Zhejiang,

People's Republic of China

\section{Z. Xiao}

Institute of Hematology and Blood Diseases

Hospital, Tianjin, People's Republic of China

Z. Shen

Shanghai Jiaotong University Medical College

Affiliated Ruijin Hospital, Shanghai,

People's Republic of China
French-American-British classification and an International Prognostic Scoring System score $\geq 0.5$ were enrolled and randomized (1:1) to one of two decitabine regimens: 3-day treatment (3-h intravenous infusion of $15 \mathrm{mg} / \mathrm{m}^{2}$ given every $8 \mathrm{~h}$ for three consecutive days/cycle/ 6 weeks) or 5-day treatment (1-h intravenous infusion of $20 \mathrm{mg} / \mathrm{m}^{2}$ once daily on days $1-5 /$ cycle/4 weeks). After a minimum of 30 patients were assigned to 3-day schedule, the remaining were assigned to the 5-day schedule. The primary efficacy endpoint was the overall

Z. Shao

Tianjin Medical University of General Hospital, Tianjin, People's Republic of China

X. Li

Shanghai 6th People's Hospital, Shanghai, People's Republic of China

X. Huang Peking University People's Hospital, Beijing, People's Republic of China

T. Liu

West China Hospital of Sichuan University, Chengdu, People's Republic of China

L. Yu

Chinese People's Liberation Army General Hospital, Beijing, People's Republic of China 
response rate (ORR). Secondary outcome measures included hematologic improvement (HI), cytogenetic response rate, the time to acute myeloid leukemia (AML) progression, and overall survival (OS).

Results: In total, 132 of 135 enrolled patients (3-day treatment, $n=36 ; 5$-day treatment, $n=99$ ) discontinued treatment (major reasons included patient withdrawal/lack of efficacy, $n=48$; adverse events, $n=23$; and disease progression, $n=22$ ). During the study, 35 of $132(26.5 \%)$ patients from the intent-to-treat (ITT) group achieved significant $(P<0.001)$ ORR [3-day group $(n=10,29.4 \%), P=0.003$; 5 -day group ( $n=25,25.5 \%), P<0.001]$. The HI rate was similar between the 3-day (47.1\%) and 5 -day groups (48.0\%). Cytogenetic response was achieved in 20 of the $30(66.7 \%)$ patients who had a baseline cytogenetic abnormality. Fifty-three (40.2\%) AML transformations or deaths occurred and the median AML-free survival time was 23.8 months for all patients from the ITT set; 24-month OS rate was $48.9 \%$. Adverse events of myelosuppression-related disorders $(85.6 \%)$ and infections (43.2\%) were commonly reported.

Conclusion: Decitabine treatment was efficacious in Chinese patients with MDS with its safety profile comparable to the global studies of decitabine conducted to date.

Funding: Xian-Janssen Pharmaceutical Ltd. China (a company of Johnson \& Johnson).

\section{J. Li}

Jiangsu Province Hospital/The First Affiliated Hospital With Nanjing Medical University, Nanjing, Jiangsu, People's Republic of China

\section{B. Chen}

Zhongda Hospital Affiliated To Southeast

University, Nanjing, People's Republic of China

H. Liang · J. Li

Xian-Janssen Pharmaceutical Ltd., Beijing, People's Republic of China
Trial registration: ClinicalTrials.gov identifier, NCT01751867.

Keywords: Chinese population; Decitabine; Hematology; Myelodysplastic syndrome (MDS); Oncology; Phase 3b

\section{INTRODUCTION}

Myelodysplastic syndromes (MDS) are a diverse group of hematopoietic disorders [1] characterized by bone marrow failure, dysplasia of the cellular elements, and a risk of progression to acute myeloid leukemia (AML) $[2,3]$. It affects about 3-4 individuals per 100,000 in the USA, with a higher prevalence (7-35 per 100,000 individuals) in the older ( $\geq 60$ years) population [4]. The incidence of MDS is low in Asian populations compared with Caucasian populations $[5,6]$, with the median age of Asian patients approximately a decade younger than the Western population [7]. MDS can be either primary (de novo) or secondary (therapy related), with the incidence of secondary MDS occurring 3-8 years after exposure to prior chemotherapy or ionizing radiation [8].

The management of MDS has always been a challenge to clinicians since the majority of the affected population consists of older patients with co-morbidities and who are generally intolerant to intensive chemotherapy. Supportive or symptomatic care remains the preferred treatment option for many patients in this category. However, the magnitude of the survival improvement offered by this approach is inadequate [9]. The only curative option available is hematopoietic stem cell transplantation; however, a limited number of patients are suitable for this procedure due to older age, the lack of a histocompatible donor, or comorbid medical factors $[10,11]$. With 
advances in research unraveling several mechanistic pathways and markers involved in the progression of the disease, a number of new treatment avenues for MDS are now being explored. A recent paradigm shift to hypomethylating agents such as azacitidine and decitabine, that are proving to alter the natural history of the disease, reduce disease-related symptoms, and improve patient quality of life, has changed the therapeutic landscape of this disease $[10,11]$.

Decitabine (5-aza-2'-deoxycytidine), a hypomethylating agent, is approved in the USA and several other countries (including China) for the treatment of previously treated or untreated, de novo or secondary MDS [12]. Decitabine is efficacious in a broad range of hematologic disorders including MDS, AML, chronic myelomonocytic leukemia (CMML), and sickle cell anemia [13-18]. A phase 3 study confirmed the superiority of decitabine versus supportive care in terms of the overall response rate (ORR; $17 \%$ vs. $0 \%$, respectively) and a longer median time to AML or death (12.1 vs. 7.8 months, respectively) [19].

In pivotal studies conducted so far, the efficacy and safety of decitabine are well determined predominately in Western population, with Asians accounting for a very small percentage (approximately up to 7\%) [19-23]. Multiple reports support the clinical and cytogenetic differences between Western and Asian patients with MDS that, to a large extent, might influence treatment outcomes, necessitating studies in an ethnicity-specific population [7, 24-27]. Recent studies conducted in Korean and Japanese populations with MDS have confirmed the efficacy and feasibility of decitabine treatment in these populations [28, 29]. The current study was designed to evaluate the efficacy, safety, and pharmacokinetics (PK) of decitabine in Chinese patients with MDS using the approved treatment schedules (3-day and 5-day), in comparison with data from the rest of the world.

\section{METHODS}

\section{Study Population}

Enrolled patients (either sex, aged $\geq 18$ years) had an MDS diagnosis (de novo or secondary) as per French-American-British

(FAB) classifications, an International Prognostic Scoring System (IPSS) score $\geq 0.5$ within 30 days of randomization, and an Eastern Cooperative Oncology Group (ECOG) performance status score of 0-2. Key exclusion criteria included: a diagnosis of AML; a history of prior malignancy; a viral or bacterial infection that was not controlled by concomitant anti-infective therapy; and an inaspirable bone marrow.

\section{Study Design}

This open-label, phase $3 \mathrm{~b}$ study was conducted from August 10, 2009 to April 26, 2013 at 12 study centers in China. A total of 132 patients were initially randomized (1:1) to either a 3-day (3-h intravenous infusion of $15 \mathrm{mg} / \mathrm{m}^{2}$ given every $8 \mathrm{~h}$ for three consecutive days/cycle/ 6 weeks) or 5-day (1-h intravenous infusion of $20 \mathrm{mg} / \mathrm{m}^{2}$ once daily on days $1-5 /$ cycle/ 4 weeks) schedule of treatment. After a minimum of 30 patients were assigned to the 3-day regimen, all remaining patients were assigned to 5-day regimen (Fig. 1). A total of 24 patients were included for PK assessment in which six patients were from 3-day dosing schedule group and 18 patients were from the 5 -day dosing group. Decitabine was available in 


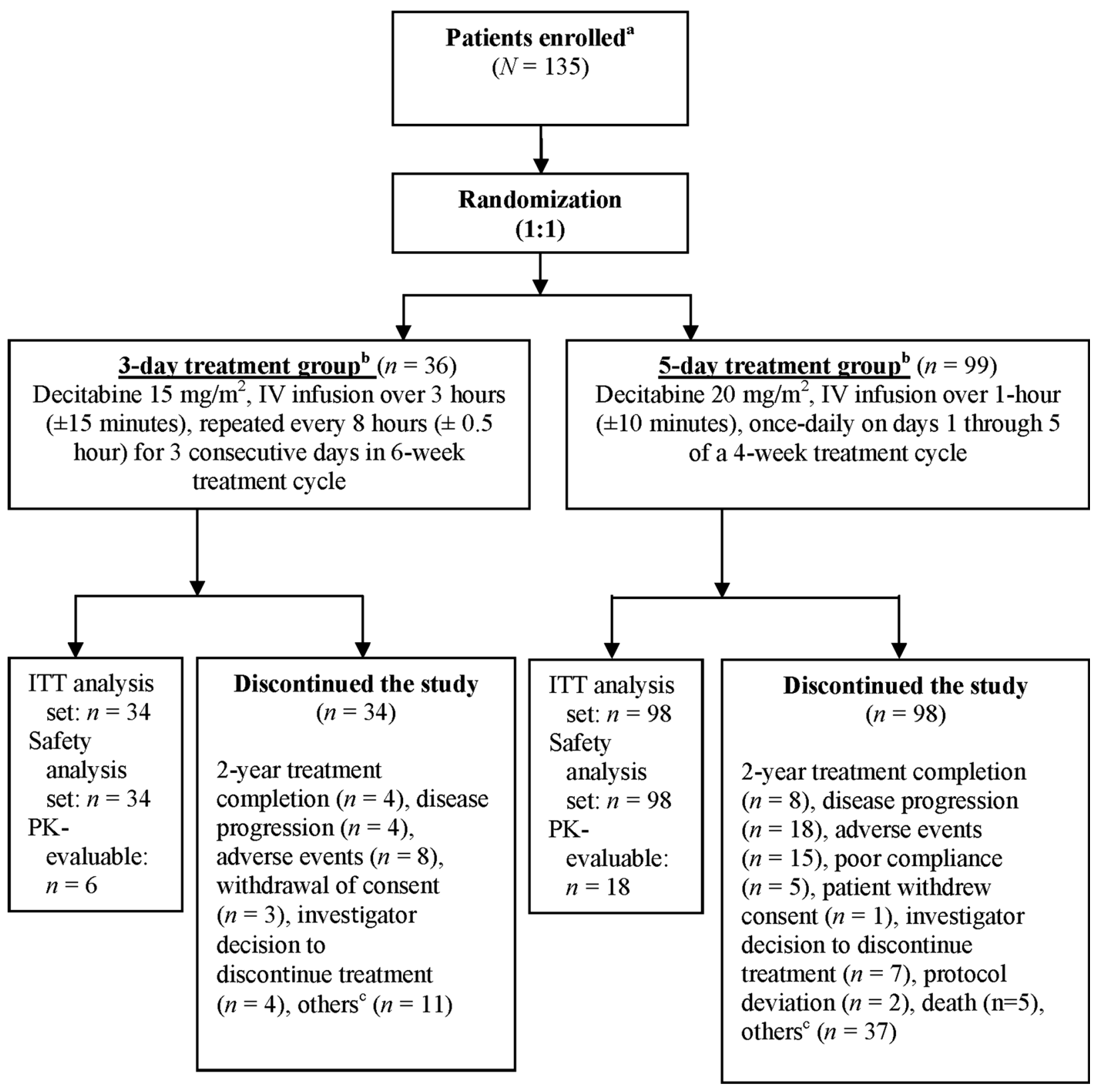

Fig. 1 Study design and patient disposition. ${ }^{a}$ After reaching a minimum of 30 patients in the intent-to-treat analysis set for the 3-day treatment group, all remaining patients were enrolled into the 5 -day treatment group. ${ }^{b}$ All patients were treated for $\geq 4$ cycles; treatment continued for a maximum of 2 years as long as patients continued to benefit. ${ }^{c}$ Other reasons: primarily included patient

the form of a sterile lyophilized powder that was reconstituted with sterile water for injection at the time of administration.

voluntary withdrawal from the study, and withdraw from the study due to economic reasons or lack of efficacy. Decitabine for injection was supplied as a sterile lyophilized powder (50 $\mathrm{mg}$ decitabine), in a single dose vial to be aseptically reconstituted prior use. ITT intent to treat, $I V$ intravenous, $P K$ pharmacokinetics

This study was conducted according to the Declaration of Helsinki, Good Clinical Practice guidelines, and other applicable regulatory 
requirements. The protocol was reviewed and approved by an Independent Ethics Committee at each study site and informed consent was obtained from each patient before enrollment. This trial is registered with ClinicalTrials.gov identifier, NCT01751867.

\section{Assessments}

\section{Efficacy Evaluations}

The primary efficacy endpoint was ORR, defined as complete response (CR) [30], partial response (PR), or marrow $\mathrm{CR}$ (mCR) as best overall response $(\mathrm{CR}+\mathrm{PR}+\mathrm{mCR})$, as per the International Working Group (IWG) 2006 criteria [intent-to-treat (ITT) analysis set] [31, 32].

Key secondary efficacy evaluations included hematologic improvement (HI) and cytogenetic response rate (CRR) as per the IWG 2006 criteria, time to AML progression (i.e., progression of MDS to AML, defined as occurrence of $>30 \%$ blasts in bone marrow) or death (calculated from the start date of treatment until disease progression to AML or death whichever occurred first), overall survival (OS), and transfusion independence. Pre-specified subgroup analyses were performed for the primary efficacy endpoint.

\section{Pharmacokinetic Evaluations}

Blood was sampled pre-dose and post-dose on day 5 for the 5-day regimen and on day 3 for the 3-day regimen. Plasma samples were analyzed for decitabine concentration using a validated liquid chromatography/tandem mass spectrometry (LC-MS/MS) method (Xeno Biotic Laboratories, China). Various PK parameters were estimated. The lower and upper limits of quantification were $1 \mathrm{ng} / \mathrm{mL}$ and $100 \mathrm{ng} / \mathrm{mL}$, respectively.

\section{Safety Evaluations}

Safety assessments included monitoring of adverse events (AEs) according to National Cancer Institute's-Common Toxicity Criteria (NCI-CTC) version 3.0, clinical laboratory tests, vital signs measurements, physical examinations, and electrocardiogram.

\section{Statistical Analysis}

All calculations were performed using the SPSS software package (version 13.0, IBM Corporation, Armonk, NY, USA). Treatment with decitabine was considered clinically meaningful if the ORR $(\mathrm{CR}+\mathrm{mCR}+\mathrm{PR})$ was $\geq 10 \%$. Based on clinical judgment from the global studies of decitabine, a 23\% ORR was expected in Chinese patients. Assuming a 10\% dropout rate, a total of 132 patients were required to assess a true ORR that was significantly different from $10 \%$, with a power of 0.9 and an alpha of 0.05 (2-sided). Normal approximation $Z$ test or exact binomial probability calculation was performed to conduct one-sample proportion comparison with the given value (10\%).

For the ORR, HI rate, and CRR, individual 95\% confidence intervals (CIs) were calculated for each treatment group and overall. Kaplan-Meier method was used to estimate the distribution of OS and the distribution of time to AML progression or death; the median time and 2-sided 95\% CI were also calculated.

\section{RESULTS}

\section{Patient Disposition and Baseline Characteristics}

Out of 135 patients enrolled in the study, 132 patients received decitabine treatment (3-day regimen, $n=34 ; 5$-day regimen, $n=98$ ) 
between August 2009 and April 2013 at 12 study centers in China. All 132 patients discontinued decitabine treatment (Fig. 1). Major reasons for discontinuation included patient withdrawal from the study due to economic reasons/lack of efficacy $[n=48 \quad(36.4 \%)]$, AEs $[n=23$ $(17.4 \%)]$, and disease progression $[n=22$ (16.7\%)].

Overall, the baseline characteristics were similar across both treatment groups except that the majority $(61.1 \%)$ of patients in the 3-day treatment group were female, in comparison with the majority of patients in the 5-day treatment group being male $(65.7 \%$; Table 1). The median age of patients was 54.1 years and the majority $(81.5 \%)$ had an ECOG performance status score of 0 or 1 , representing patients with a relatively good performance status.

\section{Extent of Exposure}

A total of 132 patients received at least 1 dose of decitabine. Overall, the median number of treatment cycles was 3 in the 3-day treatment group and 4 in 5-day treatment group. The median number of decitabine infusions was 27 (range 9-153) for the 3-day treatment group and 20 (range 4-115) for the 5-day treatment group.

\section{Concomitant Therapy}

The most common concomitant medications received by patients at least once during the entire study included granulocyte-colony stimulating factor [G-CSF, 108 (80.6\%)] and anti-infectives [124 (92.5\%)]. Patients could receive supportive therapy as needed throughout the study and commonly taken concomitant medications included anti-infectives, hematopoietic growth factors, transfusions, and antiemetic therapy.

\section{Efficacy}

\section{Primary Efficacy}

A total $35(26.5 \%)$ patients achieved an ORR $(\mathrm{CR}+\mathrm{PR}+\mathrm{mCR})$ during the study: $\mathrm{CR}$ in 13 patients (9.8\%) and mCR in 22 patients (16.7\%). All three ORRs (3-day, 5-day, and total groups) were significantly higher than the minimal clinically meaningful threshold of $10 \%$ (Table 2)

\section{Subgroup Analysis}

The ORR was lower in patients $\geq 18-60$ years of age $(19.6 \%)$ compared with patients $\geq 60$ years (42.5\%), whereas women $(24.1 \%)$ and men (28.2\%) patients generally responded equally to decitabine treatment. The treatment response was significant for the age and sex subgroups (Table 3). Although the response was similar across both treatment regimens, the ORR was significant for 5-day group (3-day, 29.4\%; 5-day, 25.5\%; $P<0.001)$. In particular, ORR varied depending upon the type of FAB classification of MDS [refractory anemia (RA), 18.2\%; refractory anemia with excess blasts (RAEB), 32.5\%; RAEB in transformation (RAEB-t), 25.0\%; CMML, 50.0\%]. Based on the IPSS risk category, the ORR was significant $(P<0.001)$ in patients from intermediate-2 (63.6\%) and intermediate-1 (18.8\%) risk groups.

\section{Secondary Efficacy}

The $\mathrm{HI}$ rate $(\mathrm{CR}+\mathrm{PR}+\mathrm{HI})$ showed no notable difference between both treatment groups (3-day regimen, 47.1\%; 5-day regimen, $48.0 \%)$. Of the 30 patients with baseline cytogenetic abnormalities, 20 patients achieved a cytogenetic response during treatment with decitabine (Table 4). Among patients who had a clinical response $(\mathrm{CR}+\mathrm{PR}+\mathrm{mCR})$, the CRR was high $(87.5 \%$, 14/16) in the ITT population. In total, 6 of 14 
Table 1 Baseline and demographic characteristics of all randomized patients

\begin{tabular}{|c|c|c|c|}
\hline Characteristic & 3-day treatment group & 5-day treatment group & Total \\
\hline \multicolumn{4}{|l|}{ Age (years) } \\
\hline$N$ & 36 & 99 & 135 \\
\hline Mean (SD) & $49.2(16.4)$ & $51.6(14.78)$ & $51.0(15.11)$ \\
\hline Median & 49.2 & 54.7 & 54.1 \\
\hline \multicolumn{4}{|l|}{ Age category, $n(\%)$} \\
\hline$\geq 18-60$ years & $25(69.4)$ & $69(69.7)$ & $94(69.6)$ \\
\hline$\geq 60$ years & $11(30.6)$ & $30(30.3)$ & $41(30.4)$ \\
\hline \multicolumn{4}{|l|}{ Sex, $n(\%)$} \\
\hline$N$ & 36 & 99 & 135 \\
\hline Men & $14(38.9)$ & $65(65.7)$ & $79(58.5)$ \\
\hline Women & $22(61.1)$ & $34(34.3)$ & $56(41.5)$ \\
\hline \multicolumn{4}{|l|}{ Race, $n(\%)$} \\
\hline$N$ & 36 & 99 & 135 \\
\hline Han & $35(97.2)$ & $99(100.0)$ & $134(99.3)$ \\
\hline Others & $1(2.8)$ & $0(0.0)$ & $1(0.7)$ \\
\hline \multicolumn{4}{|l|}{ Body weight (kg) } \\
\hline$N$ & 36 & 99 & 135 \\
\hline Mean (SD) & $63.8(9.19)$ & $63.1(10.81)$ & $63.3(10.37)$ \\
\hline \multicolumn{4}{|l|}{ Duration of MDS (months) } \\
\hline$N$ & 34 & 98 & 132 \\
\hline Median $(\min -\max )$ & $0.6(0.1-26.6)$ & $0.7(0.0-52.0)$ & $0.7(0.0-52.0)$ \\
\hline \multicolumn{4}{|c|}{ Patients with prior active MDS therapy, $n$} \\
\hline$N$ & 24 & 44 & $68(50 \%)$ \\
\hline Chemotherapy & 8 & 13 & $21(16 \%)$ \\
\hline Biologic $^{a}$ & 15 & 26 & $41(30 \%)$ \\
\hline Bone marrow transplant & 0 & 0 & 0 \\
\hline \multicolumn{4}{|c|}{ FAB classification of MDS, $n$ (\%) } \\
\hline$N$ & 36 & 99 & 135 \\
\hline RA & $11(30.6)$ & $16(16.2)$ & $27(20.0)$ \\
\hline RARS & $0(0.0)$ & $4(4.0)$ & $4(3.0)$ \\
\hline RAEB & $18(50.0)$ & $67(67.7)$ & $85(63.0)$ \\
\hline RAEB-t & $4(11.1)$ & $7(7.1)$ & $11(8.1)$ \\
\hline CMML & $3(8.3)$ & $5(5.1)$ & $8(5.9)$ \\
\hline
\end{tabular}


Table 1 continued

\begin{tabular}{llll}
\hline Characteristic & 3-day treatment group & 5-day treatment group & Total \\
\hline IPSS score, $n(\%)^{\mathrm{b}}$ & & & \\
$N$ & 36 & 99 & 135 \\
Intermediate-1 risk (0.5-1.0 points) & $18(50.0)$ & $39(39.4)$ & $57(42.2)$ \\
Intermediate-2 risk (1.5-2.0 points) & $11(30.6)$ & $47(47.5)$ & $58(43.0)$ \\
High risk $\geq 2.5$ points) & $7(19.4)$ & $13(13.1)$ & $20(14.8)$ \\
ECOG score, $n(\%)$ & & & 135 \\
$N$ & 36 & 99 & $19(14.1)$ \\
0 & $8(22.2)$ & $11(11.1)$ & $91(67.4)$ \\
1 & $20(55.6)$ & $71(71.7)$ & $25(18.5)$ \\
\hline
\end{tabular}

$C M M L$ chronic myelomonocytic leukemia, ECOG Eastern Cooperative Oncology Group, FAB French-American-British, IPSS International Prognostic Scoring System, $M D S$ myelodysplastic syndrome, $R A$ refractory anemia, $R A E B$ refractory anemia with excess blasts, $R A E B-t$ refractory anemia with excess blasts in transformation, $R A R S$ refractory anemia with ringed sideroblasts, $S D$ standard deviation

a Growth factors, immunosuppressive agents, hormones

b Determined by complete blood cell count, bone marrow assessment, and bone marrow cytogenetics within 30 days of randomization

Table 2 The overall response rates of patients (ITT analysis set)

\begin{tabular}{llll}
\hline & $\begin{array}{l}\text { 3-day treatment group } \\
(\boldsymbol{n}=\mathbf{3 4})\end{array}$ & $\begin{array}{l}\text { 5-day treatment group } \\
(\boldsymbol{n}=\mathbf{9 8})\end{array}$ & $\begin{array}{l}\text { Overall } \\
(\boldsymbol{N}=\mathbf{1 3 2})\end{array}$ \\
\hline$n$ & 10 & 25 & 35 \\
$\mathrm{ORR}, \%(95 \% \mathrm{CI})$ & $29.4(15.1,47.5)^{\mathrm{a}}$ & $25.5(17.2,35.3)^{\mathrm{b}}$ & $26.5(19.2,34.9)^{\mathrm{b}}$ \\
$\mathrm{CR}, n(\%)$ & $3(8.8)$ & $10(10.2)$ & $13(9.8)$ \\
$\mathrm{PR}, n(\%)$ & $\mathrm{NA}$ & $\mathrm{NA}$ & $\mathrm{NA}$ \\
$\mathrm{mCR}, n(\%)$ & $7(20.6)$ & $15(15.3)$ & $22(16.7)$ \\
\hline
\end{tabular}

$P$ value calculated using single sample test using exact binomial proportion test, $p_{0}=10 \%$. ITT analysis set included all patients who received at least 1 dose of decitabine

$\mathrm{ORR}=\mathrm{CR}+\mathrm{PR}+\mathrm{mCR}$

$C I$ confidence interval, $C R$ complete response, $I T T$ intent to treat, $m C R$ marrow complete response, $O R R$ overall response rate, $P R$ partial response

a $P=0.003$

b $P<0.001$

non-responders achieved a cytogenetic response. Of 66 patients who achieved clinical response, approximately $69 \%$ had occurred at the end of second cycle. Approximately $44 \%$ of patients achieved the best response in the first two cycles (Fig. 2).

The median time to AML progression or death was 23.8 months (5-day regimen, 
Table 3 Subgroup analyses of overall response rate (ITT analysis set)

\begin{tabular}{llll}
\hline Subgroups & $\begin{array}{l}\text { Total number of } \\
\text { patients in subgroup }\end{array}$ & $\begin{array}{l}\text { Patients with ORR } \\
(\mathbf{C R}+\mathbf{P R}+\mathbf{m C R})\end{array}$ & ORR, \% (95\% CI) \\
\hline Age category & & & $19.6(12.0,29.1)^{\mathrm{a}}$ \\
$\geq 18-60$ years & 92 & 18 & $42.5(27.0,59.1)^{\mathrm{b}}$ \\
$\geq 60$ years & 40 & 17 & \\
Sex & & & $28.2(18.6,39.5)^{\mathrm{b}}$ \\
Men & 78 & 22 & $24.1(13.5,37.6)^{\mathrm{a}}$
\end{tabular}

Treatment group

$\begin{array}{llll}\text { 3-day group } & 34 & 10 & 29.4(15.1,47.5)^{\mathrm{c}} \\ 5 \text {-day group } & 98 & 25 & 25.5(17.2,35.3)^{\mathrm{b}}\end{array}$

FAB classification

\begin{tabular}{lrrl} 
RA & 27 & 3 & $18.2(2.3,51.8)$ \\
RARS & 4 & 0 & 0 \\
RAEB & 83 & 27 & $32.5(22.6,43.7)^{\mathrm{b}}$ \\
RAEB-t & 11 & 2 & $25.0(0.6,80.6)$ \\
CMML & 7 & 3 & $50.0(1.3,98.7)$ \\
IPSS risk group & & & \\
Intermediate-1 & 55 & 14 & $18.8(4.0,45.6)^{\mathrm{b}}$ \\
Intermediate-2 & 57 & 15 & $63.6(30.8,89.1)^{\mathrm{b}}$ \\
High & 20 & 6 & $42.9(9.9,81.6)$ \\
\hline
\end{tabular}

$\mathrm{ORR}=\mathrm{CR}+\mathrm{PR}+\mathrm{mCR}$

$P$ value calculated using single sample test using exact binomial proportion test, $p_{0}=10 \%$

ITT analysis set included all patients who received at least 1 dose of decitabine

$C I$ confidence interval, $C M M L$ chronic myelomonocytic leukemia, $C R$ complete response, IPSS International Prognostic Scoring System, ITT intent to treat, $m C R$ marrow complete response, $O R R$ overall response rate, $P R$ partial response, $R A$ refractory anemia, $R A E B$ refractory anemia with excess blasts, $R A E B-t$ refractory anemia with excess blasts in transformation, RARS refractory anemia with ringed sideroblasts

a $P<0.05$

b $P<0.001$

${ }^{c} P=0.003$

21.4 months; 3-day regimen, not reached; Table 4). The maximum AML-free survival time was 39.8+ months in 3-day regimen and
$43.4+$ months in 5-day regimen, but both were censored observations (it was not known whether patients had died or progressed to 
Table 4 Summary of secondary endpoint results (ITT analysis set)

\begin{tabular}{|c|c|c|c|c|c|c|}
\hline \multirow{3}{*}{$\begin{array}{l}\text { Endpoint } \\
\mathrm{CR}+\mathrm{PR}+\mathrm{HI}^{\mathrm{a}}(95 \% \mathrm{CI})\end{array}$} & \multirow{2}{*}{\multicolumn{2}{|c|}{$\begin{array}{l}3 \text {-day treatment } \\
\text { group }(n=34) \\
n\end{array}$}} & \multirow{2}{*}{\multicolumn{2}{|c|}{$\begin{array}{l}5 \text {-day treatment } \\
\text { group }(n=98) \\
n\end{array}$}} & \multirow{2}{*}{\multicolumn{2}{|c|}{$\begin{array}{l}\text { Total }(N=132) \\
n\end{array}$}} \\
\hline & & & & & & \\
\hline & 16 & $47.1(29.8,64.9)$ & 47 & $48.0(37.8,58.3)$ & 63 & $47.7(39.0,56.6)$ \\
\hline $\mathrm{HI}^{\mathrm{b}}(95 \% \mathrm{CI})$ & 13 & $38.2(22.2,56.4)$ & 37 & $38.1(28.5,48.6)$ & 50 & $38.2(29.8,47.1)$ \\
\hline \multicolumn{7}{|l|}{ Cytogenetic response rate } \\
\hline Overall population & 6 & $4(66.7)$ & 24 & $16(66.7)$ & 30 & $20(66.7)$ \\
\hline $\begin{array}{l}\text { Responders evaluated by clinical efficacy } \\
\text { assessment }(\mathrm{CR}+\mathrm{mCR}+\mathrm{PR}), n(\%)\end{array}$ & 3 & $3(100.0)$ & 13 & $11(84.6)$ & 16 & $14(87.5)$ \\
\hline Best response as $\mathrm{CR}$ & 2 & $2(100.0)$ & 3 & $2(66.7)$ & 5 & $4(80.0)$ \\
\hline Best response $\mathrm{mCR}$ & 1 & $1(100.0)$ & 10 & $9(90.0)$ & 11 & $10(90.9)$ \\
\hline Non-responders evaluated by clinical efficacy & 3 & $1(33.3)$ & 11 & $5(45.5)$ & 14 & $6(42.9)$ \\
\hline $\begin{array}{l}\text { Time to AML transformation }{ }^{c} \text { or death } \\
\text { (months) }\end{array}$ & 34 & & 98 & & 132 & \\
\hline Event (AML or death) occurs & & $9(26.5)$ & & $44(44.9)$ & & $53(40.2)$ \\
\hline Censored & & $25(73.5)$ & & $54(55.1)$ & & $79(59.8)$ \\
\hline Median time & & - & & 21.4 & & 23.8 \\
\hline Overall survival $^{\mathrm{d}}$ & 34 & & 98 & & 132 & \\
\hline Death & & $16(47.1)$ & & $58(59.2)$ & & $74(56.1)$ \\
\hline Censored & & $18(52.9)$ & & $40(40.8)$ & & $58(43.9)$ \\
\hline \multicolumn{7}{|l|}{ Survival rate $(\%)$} \\
\hline 6-month $(95 \% \mathrm{CI})$ & & $91.1(74.8,97.0)$ & & $84.7(75.9,90.5)$ & & $86.3(79.1,91.1)$ \\
\hline 12-month (95\% CI) & & $75.9(57.5,87.2)$ & & $65.9(55.5,74.4)$ & & $68.4(59.7,75.7)$ \\
\hline 18-month $(95 \% \mathrm{CI})$ & & $69.3(50.3,82.2)$ & & $53.7(43.1,63.2)$ & & $57.6(48.5,65.7)$ \\
\hline 24-month (95\% CI) & & $62.0(42.6,76.5)$ & & $44.6(34.3,54.4)$ & & $48.9(39.8,57.4)$ \\
\hline \multicolumn{7}{|l|}{ Transfusion independence, $N(\%)$} \\
\hline Baseline (before first dose of decitabine) & 34 & $7(20.6)$ & 98 & $37(37.8)$ & 132 & $44(33.3)$ \\
\hline Treatment phase & 34 & $18(52.9)$ & 97 & $47(48.5)$ & 131 & $65(49.6)$ \\
\hline
\end{tabular}

ITT analysis set included all patients who received at least 1 dose of decitabine $A M L$ acute myeloid leukemia, $C I$ confidence interval, $C R$ complete response, $H I$ hematological improvement, $I T T$ intent to treat, $m C R$ marrow complete response, $P R$ partial response

${ }^{a}$ Improvement rate was calculated with total ITT patients of each treatment group as denominator

b Proportion of patients with simple hematological improvement $(\mathrm{HI})$ as the best response calculated in total ITT patients of each treatment group as denominator (excluding patients with all cell lines assessed as 'not applicable' at second treatment cycle, e.g., patients with normal hematology at baseline); patients who showed improvement in any of the 3 lineages were counted in the numerator

${ }^{c}$ Progression of MDS to AML; defined as the occurrence of $>30 \%$ blasts in bone marrow

${ }^{\mathrm{d}}$ Using Kaplan-Meier method 


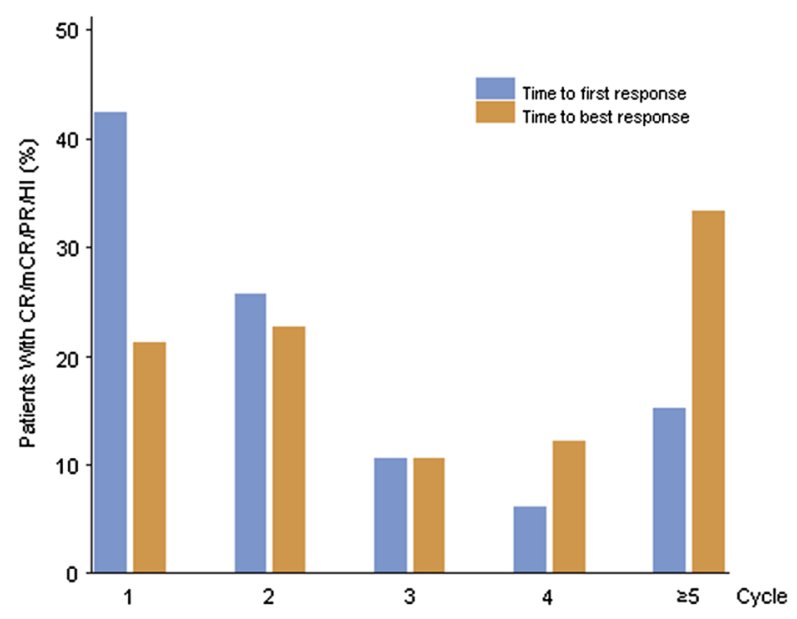

Fig. 2 Time to the first and best response-combining both treatment groups (ITT analysis set). Only patients with remission were included in the analysis. $C R$ complete remission, $H I$ hematologic improvement, ITT intent to treat, $m C R$ marrow complete remission, $P R$ partial remission

AML). In total, 53 AML progressions or deaths occurred. According to IPSS classification, the median time to AML transformation or death was 24.3 months and 8.4 months for the intermediate- 2 and high risk groups, respectively (not reached for intermediate-1 risk group; Fig. 3). The rate of AML-free survival at 1 year was $76.4 \%$ in the intermediate-1 risk group, $70.0 \%$ in the intermediate- 2 risk group, and $41.4 \%$ in the high risk group.

Of the total patients treated with decitabine $(N=132)$, OS rates for months $6,12,18$, and 24 were $86.3,68.4,57.6$, and $48.9 \%$, respectively. Kaplan-Meier survival curves showing survival times are shown in Fig. 4. The median OS was 23.8 months for all treated patients: 32.3 months (3-day regimen) and 20.6 months (5-day regimen). A total of 74 deaths occurred during the study (3-day regimen, 16; 5-day regimen, 58). As per IPSS classification, patients from the intermediate-1 risk group had a longer median survival than those from the intermediate- 2 risk or high risk groups, respectively (30.7 vs. 24.3 or 10.8 months, $P=0.020$; Fig. 5).

A patient was considered to be transfusion independent, if transfusion of red blood cells or platelets was not required for an eight-week period before the first dose of decitabine and during the study. For all patients, the transfusion independence rate at baseline was $33.3 \%$, which increased to $49.6 \%$ during the treatment phase. In both treatment groups, the number of transfusion-independent patients increased during the decitabine treatment phase versus baseline (3-day regimen, 52.9\% vs. $20.6 \%$, respectively; 5 -day regimen, $48.5 \%$ vs. $37.8 \%$, respectively). Of the 88 transfusion-dependent patients at baseline, 50 remained transfusion dependent while the remaining 38 patients were transfusion independent by the end of treatment. Of the 44 transfusion-independent patients at baseline, 27 patients continued to be transfusion independent and 16 patients became transfusion dependent at the end of treatment (Table 5).

\section{Pharmacokinetics}

The mean (standard deviation) plasma concentration-time profiles for both treatment groups are shown in Figs. 6 and 7. In the 5-day treatment group, the mean observed maximum plasma concentration $\left(C_{\max }\right)$ and area under curve (AUC) values on last day of the treatment (day 5) were markedly higher than in 3-day treatment group; the mean time when $C_{\max }$ was observed $\left(T_{\max }\right)$ was lower in 5-day treatment group than in 3-day treatment group (Table 6). Plasma decitabine concentrations were measurable up to $6 \mathrm{~h}$ post-dose in patients treated with the 3-day regimen and up to $4 \mathrm{~h}$ (the last sample time) in those from the 5-day regimen. 
No. Patients Left Intermediate-1 risk Intermediate-2 risk High risk

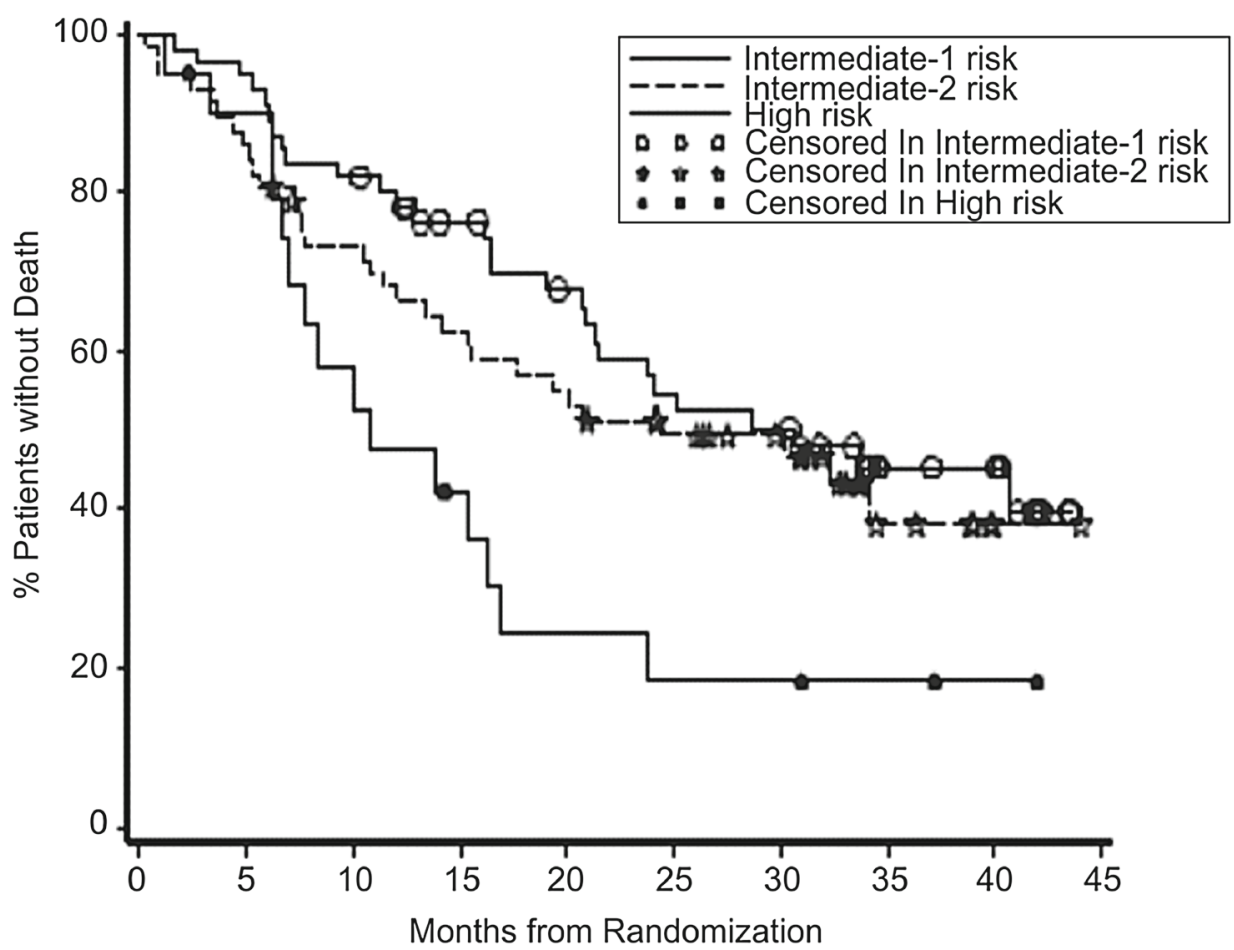

$\begin{array}{rrrrrrrrrr}55 & 52 & 45 & 37 & 31 & 25 & 23 & 12 & 11 & 0 \\ 57 & 49 & 40 & 34 & 30 & 24 & 19 & 6 & 1 & 0 \\ 20 & 17 & 10 & 7 & 4 & 3 & 3 & 2 & 1 & 0\end{array}$

\begin{tabular}{lccc}
\hline Time to AML & Intermediate-1 risk & Intermediate-2 risk & High risk \\
\hline Number assessed & 55 & 57 & 20 \\
Median $(95 \% \mathrm{CI})$ & $-(19.0)$, & $24.3(15.5)$, & $8.4(4.7,16.3)$ \\
6-month event-free rate $(95 \% \mathrm{CI})$ & $92.4(81.0,97.1)$ & $80.1(66.9,88.5)$ & $67.4(41.0,84.0)$ \\
12-month event-free rate $(95 \% \mathrm{CI})$ & $76.4(61.1,86.3)$ & $70.0(54.7,81.0)$ & $41.4(18.1,63.4)$ \\
18-month event-free rate $(95 \% \mathrm{CI})$ & $69.7(52.8,81.6)$ & $61.1(44.6,74.0)$ & $20.7(5.2,43.2)$ \\
24-month event-free rate $(95 \% \mathrm{CI})$ & $62.2(44.0,76.0)$ & $51.9(35.2,66.2)$ & $10.3(0.8,34.3)$ \\
Overall $P$ value & $<0.001$ & & \\
Hazard ratio $(95 \% \mathrm{CI})$ & $0.27(0.13,0.56)$ & $0.37(0.19,0.73)$ & \\
\hline
\end{tabular}

Fig. 3 Kaplan-Meier survival curves showing time to AML transformation or death after combining both treatment groups by IPSS classification (ITT analysis set). Hazard ratio is from nonstratified proportional

\section{Safety}

The most common ( $\geq 40 \%$ ) AE was a decrease in white blood cell (WBC) count (67.4\%), followed hazards model. $P$ value is from a nonstratified $\log$-rank test. $A M L$ acute myeloid leukemia, $C I$ confidence interval, IPSS International Prognostic Scoring System, ITT intent to treat

by a decreased platelet count (59.1\%), decreased neutrophil count (54.5\%) count, and decrease in hemoglobin (43.9\%). Seven patients had AEs leading to death (3-day regimen, 1; 5-day 


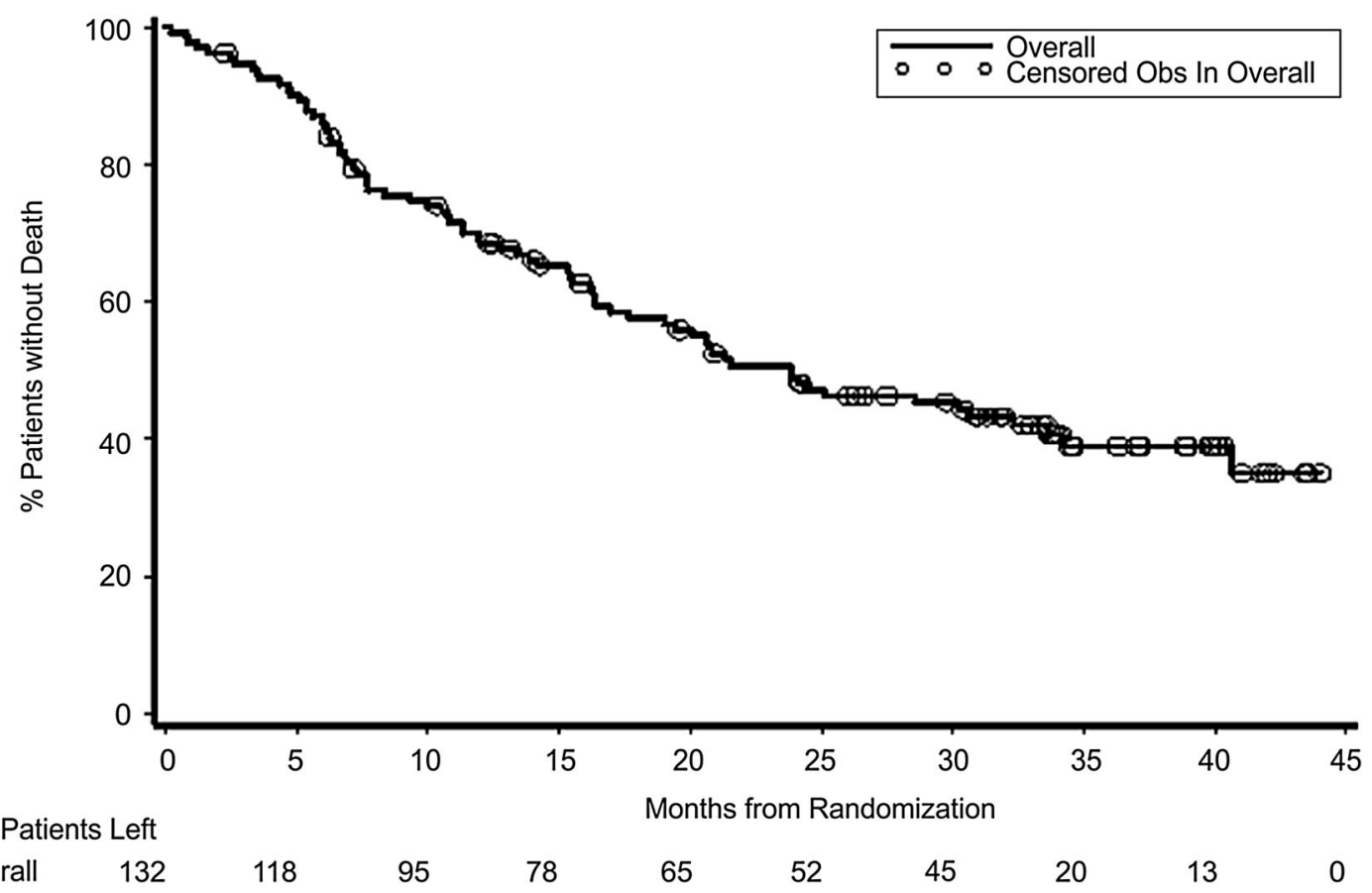

Fig. 4 Kaplan-Meier survival curves showing survival time after combining both treatment groups (intent-to-treat analysis set)

regimen, 6). Serious AEs were reported in 34 (25.8\%) patients [3-day regimen, 8 (23.5\%); 5-day regimen, $26(26.5 \%)]$. Grade 3 or higher leukopenia (68.1\%) and thrombocytopenia $(61.4 \%)$ were frequently observed (Table 7$)$. A total of 18 patients (3-day regimen, 6; 5-day regimen, 12) discontinued the study due to AEs and most commonly due to pneumonia [6 (4.5\%)]. Clinically significant hematologic abnormalities were related to hemoglobin, WBCs, neutrophil count, and neutrophil percentage. AEs of myelosuppression-related disorders and infections were observed in $85.6 \%$ and $43.2 \%$ of patients, respectively.

\section{DISCUSSION}

Myelodysplastic syndromes with poor prognosis and limited therapeutic modalities have long been a challenging area for researchers and clinicians propelling the advent of new strategies that could address the unmet needs.
With the introduction of hypomethylation agents, the therapeutic scenario for MDS has evolved tremendously, which presents a hope for better disease control and improved quality of life in these patients $[2,33,34]$. This study was designed to evaluate the efficacy and safety of decitabine in the Chinese population. With decitabine being established as a potential therapeutic tool in the Western population $[19,21,22]$, the results of this study may encourage use of decitabine in Chinese/Asian populations, who represent a different clinical and cytogenetic profile than Caucasian patients $[7,24-27,35,36]$. The patients enrolled in this study had a median age of 54.1 years, all having de novo MDS and the majority of intermediate- 1 or intermediate- 2 risk.

Myelodysplastic syndromes constitute varied disease conditions ranging from more indolent forms to those with a rapid evolution of AML [2, 3 , 37]. From the clinical perspective, delaying the time to AML or death is a prime objective 


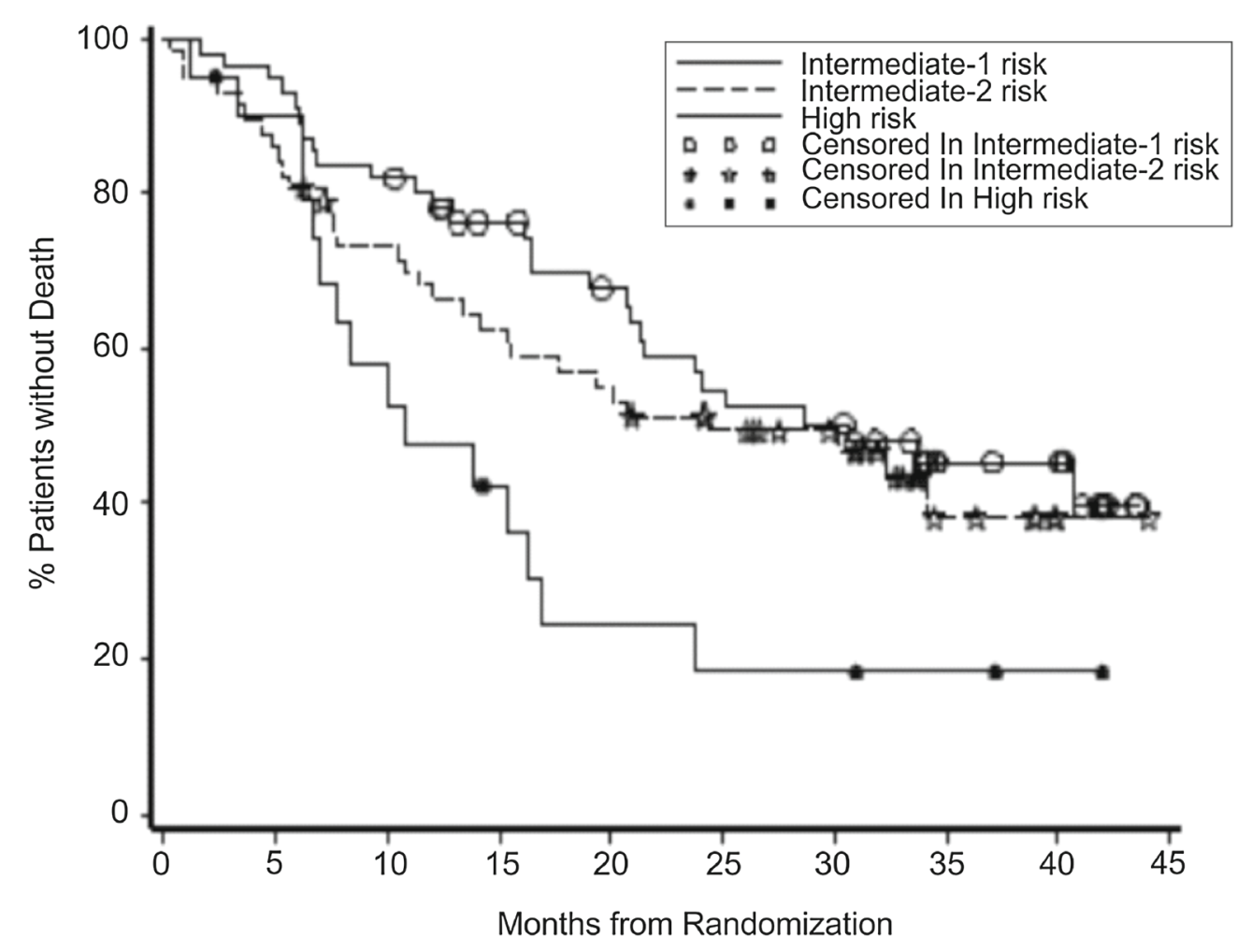

No. Patients Left Intermediate-1 risk Intermediate-2 risk High risk

$\begin{array}{rrrrrrrrrr}55 & 52 & 45 & 37 & 31 & 25 & 23 & 12 & 11 & 0 \\ 57 & 49 & 40 & 34 & 30 & 24 & 19 & 6 & 1 & 0 \\ 20 & 17 & 10 & 7 & 4 & 3 & 3 & 2 & 1 & 0\end{array}$

\begin{tabular}{lccc}
\hline Overall survival & Intermediate-1 risk & Intermediate-2 risk & High risk \\
\hline Number assessed & 55 & 57 & 20 \\
Median $(95 \% \mathrm{CI})$ & $30.7(20.8)$, & $24.3(14.2)$, & $10.8(6.6,17.0)$ \\
6-month event-free rate $(95 \% \mathrm{CI})$ & $90.9(79.5,96.1)$ & $80.7(67.9,88.8)$ & $89.7(64.8,97.3)$ \\
12-month event-free rate $(95 \% \mathrm{CI})$ & $78.1(64.7,86.9)$ & $66.1(52.1,76.9)$ & $47.5(24.5,67.4)$ \\
18-month event-free rate $(95 \% \mathrm{CI})$ & $69.8(55.4,80.3)$ & $56.9(42.9,68.7)$ & $24.1(7.8,45.2)$ \\
24-month event-free rate $(95 \% \mathrm{CI})$ & $56.8(41.9,69.2)$ & $51.4(37.6,63.6)$ & $18.1(4.6,38.7)$ \\
Overall $P$ value & 0.020 & & \\
Hazard ratio $(95 \% \mathrm{CI})$ & $0.42(0.22,0.79)$ & $0.52(0.28,0.96)$ & \\
\hline
\end{tabular}

Fig. 5 Kaplan-Meier curves of the overall survival rate according to IPSS classification (intent-to-treat analysis set). $P$ value is from a nonstratified log-rank test. Hazard

while designing a therapeutic strategy for patients with MDS (especially with those at high risk). The median time to AML or death was almost double in the Chinese population (23.8 months) than in Caucasian population ratio is from nonstratified proportional hazards model. $C I$ confidence interval, IPSS International Prognostic Scoring System

(12.1 months) [19]. According to subgroup analysis as per IPSS classification, the risk of AML transformation or death had reduced in the intermediate- 1 and intermediate- 2 risk groups compared with the high risk group. 

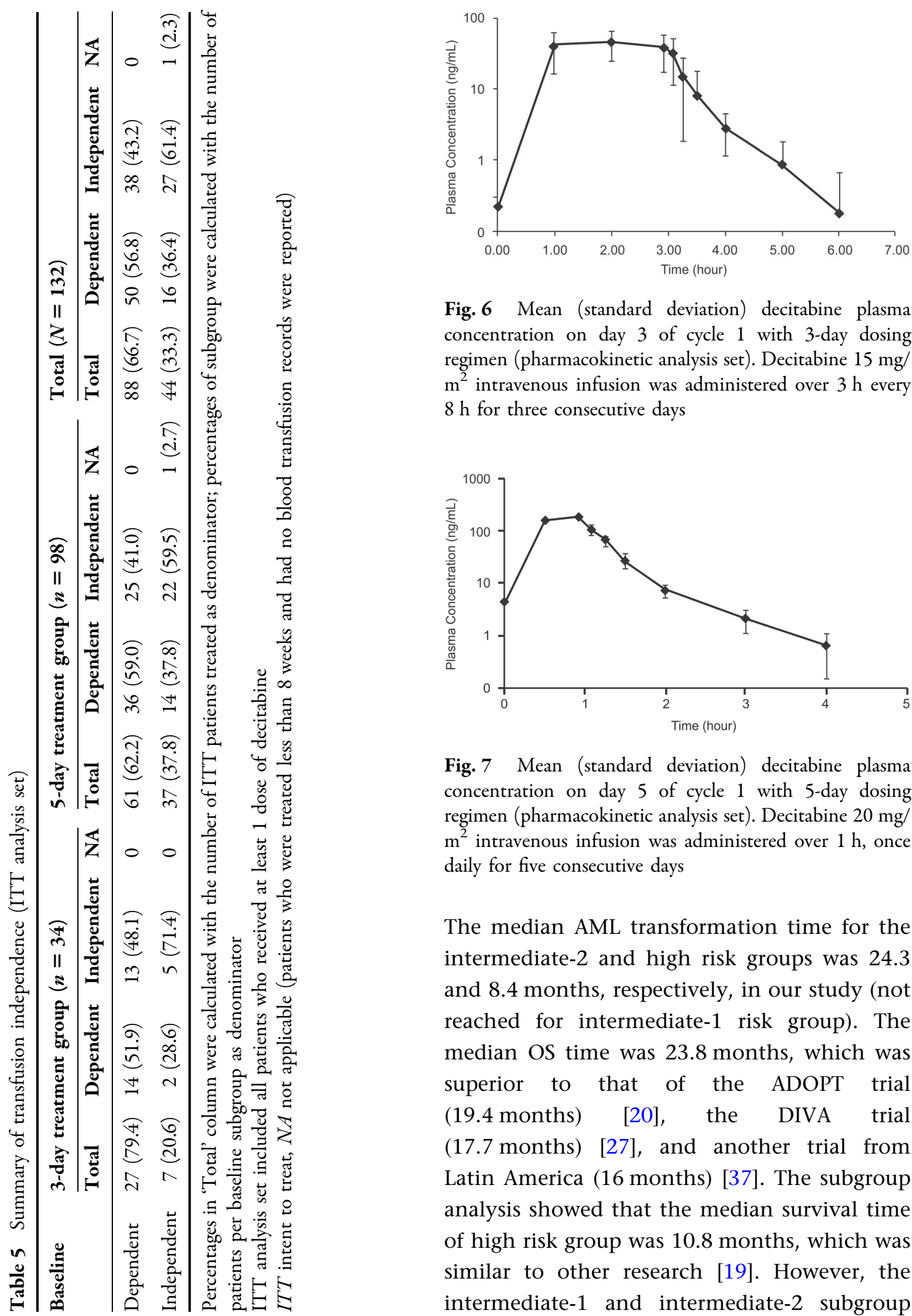

Fig. 6 Mean (standard deviation) decitabine plasma concentration on day 3 of cycle 1 with 3 -day dosing regimen (pharmacokinetic analysis set). Decitabine $15 \mathrm{mg} /$ $\mathrm{m}^{2}$ intravenous infusion was administered over $3 \mathrm{~h}$ every $8 \mathrm{~h}$ for three consecutive days

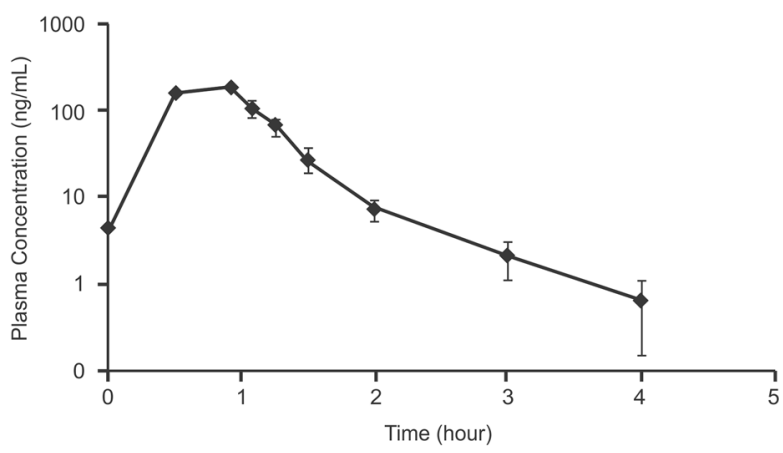

Fig. 7 Mean (standard deviation) decitabine plasma concentration on day 5 of cycle 1 with 5-day dosing regimen (pharmacokinetic analysis set). Decitabine $20 \mathrm{mg} /$ $\mathrm{m}^{2}$ intravenous infusion was administered over $1 \mathrm{~h}$, once daily for five consecutive days

The median AML transformation time for the intermediate- 2 and high risk groups was 24.3 and 8.4 months, respectively, in our study (not reached for intermediate-1 risk group). The median OS time was 23.8 months, which was superior to that of the ADOPT trial (19.4 months) [20], the DIVA trial (17.7 months) [27], and another trial from Latin America (16 months) [37]. The subgroup analysis showed that the median survival time of high risk group was 10.8 months, which was similar to other research [19]. However, the intermediate- 1 and intermediate- 2 subgroup 
Table 6 Pharmacokinetic summary of decitabine following 3-day treatment and 5-day treatment (pharmacokinetic analysis set)

\begin{tabular}{lccccc}
\hline Treatment & $\boldsymbol{C}_{\mathbf{m a x}}(\mathbf{n g} / \mathbf{m L})$ & $\boldsymbol{T}_{\max }(\mathbf{h})$ & $\mathbf{A U C}_{\text {last }}(\mathbf{n g ~ h} / \mathbf{m L})$ & $\mathbf{A U C}_{\mathbf{0}-\infty}(\mathbf{n g ~ h} / \mathbf{m L})$ & $\boldsymbol{T}_{\mathbf{1 / 2}}(\mathbf{h})$ \\
\hline 3-day treatment & $(n=6)$ & & & & \\
Mean & 54.44 & 2.43 & 117.84 & 118.93 & 0.58 \\
SD & 20.07 & 0.79 & 50.37 & 50.55 & 0.22 \\
CV\% & 36.87 & 32.51 & 42.74 & 42.50 & 38.42 \\
5-day treatment & $(n=18)$ & & & & \\
Mean & 222.35 & 0.88 & 179.23 & 180.43 & 0.63 \\
SD & 53.74 & 0.24 & 43.84 & 43.78 & 0.18 \\
CV\% & 24.17 & 27.67 & 24.46 & 24.26 & 29.13 \\
\hline
\end{tabular}

Pharmacokinetic analysis set included all patients who were randomized and participated in the pharmacokinetic assessments

$A U C$ Area under curve, $C_{\max }$ Observed maximum plasma concentration, $C V$ Coefficient of variation, $T_{1 / 2}$ Terminal half-life, $T_{\max }$ Time when $\mathrm{C}_{\max }$ was observed

a $15 \mathrm{mg} / \mathrm{m}^{2}$ administered over $3 \mathrm{~h}$ as an intravenous infusion every $8 \mathrm{~h}$ for 3 consecutive days

b $20 \mathrm{mg} / \mathrm{m}^{2}$ administered over $1 \mathrm{~h}$ as an intravenous infusion once- daily for 5 consecutive days

Table 7 Summary of adverse events occurring in $\geq 10 \%$ patients (safety set)

\begin{tabular}{lll}
\hline Adverse events & Patients $(\boldsymbol{N}=\mathbf{1 3 2})$ & Grade $\mathbf{2 3}$ \\
\cline { 2 - 3 } & Grade 1-2 & \\
\hline Hematologic, $n$ (\%) & & $90(68.1)$ \\
Leukopenia & $5(3.8)$ & $81(61.4)$ \\
Thrombocytopenia & $3(2.3)$ & $71(53.8)$ \\
Neutropenia & $2(1.5)$ & $57(43.2)$ \\
Anemia & $7(5.3)$ & \\
Non-hematologic, $n(\%)$ & & $3(2.3)$ \\
Alanine aminotransferase increased & $25(18.9)$ & $14(10.6)$ \\
Upper respiratory tract infection & $31(23.5)$ & $13(9.8)$ \\
Lung infection & $20(15.2)$ & $15(11.4)$ \\
Pneumonia & $9(6.8)$ & \\
\hline
\end{tabular}

All observed toxicities were to be graded according to the National Cancer Institute Common Toxicity Criteria for Adverse Events (NCI CTCAE), version 3.0, 2008 [41]

Safety analysis set included all patients who received at least 1 dose of decitabine

outcome was significantly better than other populations (30.7 and 24.3 months, respectively) [20,37]. The reason may be due to the lower rate of abnormal chromosomes in these two subgroups $(39 \%$ and 55\%, respectively) compared with the high risk 
group (75\%). According to the cytogenetic prognosis grading, the proportion of poor prognosis for chromosome in the two subgroups was $6 \%$ and $38 \%$, respectively, which was much lower than $50 \%$ in the high risk group. Meanwhile, the proportion of concomitant disease in the two subgroup patients was also lower $(47.4 \%$ and $62.1 \%$, respectively) than the high risk group (75\%) which may partly be responsible for the outcome.

One-year OS rate (68.4\%) observed in this study was almost similar to that in the USA (66\%) and Korean populations (74.8\%) [28]. Further, two-year survival rate of this trial (48.9\%) was superior to South American (37\%) [37] and Korean studies (42.2\%) [38]. Collectively, these studies suggest efficacious benefits of decitabine treatment in Asian populations. Furthermore, the two treatment regimens of decitabine from this study demonstrated significantly higher ORR [26.5\% (CR, 9.8\%; mCR, 16.7\%)] than the minimal clinically meaningful threshold of $10 \%$. When compared with earlier pivotal studies (including ADOPT) [21, 22], the ORR in Caucasian patients was higher [up to $32 \%(\mathrm{CR}, 17 \%)$ ] than that observed in Chinese patients from our study. Notably, the number of treatment cycles in the aforementioned study was also higher (6 or more courses) compared with our study (3.9 courses), which probably explains the difference in the treatment response in these two patient populations. Re-emphasizing the need for prolonged therapy, the DIVA study in Korean patients with MDS, which used a median of 5 treatment cycles, demonstrated a noticeably higher ORR [CR + PR + mCR; 36.6\% (CR, 12.9\%)] [28] than in this study. Similarly, in Japanese patients with MDS, decitabine (six treatment cycles) demonstrated an ORR of $32.4 \%$ (CR, 18.9\%) [29]. Moreover, the percentage of patients who had received prior active MDS therapy was up to $48 \%$, especially the chemotherapy account for $16 \%$, which exceeds that of other reports [18, 20, 37]. Importantly, the baseline clinical characteristics of patients in the current study indicate that they may have been in a worse disease status than other populations; this may, therefore, partly result in the observed CR differences when compared to the other trials.

Hypomethylation of DNA is associated with an alteration in hematological status that predicts the clinical response to treatment [39]. In this study, approximately $38.2 \%$ of patients showed a $\mathrm{HI}$ after the first dose of decitabine, which lasted until the end of treatment and which, in comparison with the Korean population, was slightly low (47.5\%) [28]. In patients who were responders as evaluated by clinical efficacy assessment and in patients with CR as best response, the CRR, indicating the potential to alter the natural history of the disease, was marginally higher in Chinese patients $(66.7 \%)$ compared to that in the ADOPT study in Caucasian patients (52\%) [21]. Of note in this study, 69\% of patients achieved clinical response at the end of second cycle and approximately $44 \%$ of patients achieved the best response in the first 2 cycles.

Patients with MDS eventually depend on chronic transfusions, which provide hematological stability; however, transfusion-related morbidities due to iron overload are of significant medical concern [40]. Thus, reducing the transfusion dependency in patients would add to the treatment benefits. The transfusion independence rate improved significantly compared to baseline during treatment with decitabine.

No unexpected safety findings were observed in this Chinese population. The primary AEs 
noted were those of myelosuppression and complications resulting from cytopenias. The incidence of grade 3 or higher cytopenias during treatment as well as infectious complications appears similar to those seen with the approved decitabine regimen. Overall, incidences of deaths and serious AEs were low. AEs leading to discontinuation were slightly higher in the 3-day dosing schedule compared with the 5-day dosing regimen, which possibly correlates with the extent of study drug exposure. Overall, the safety outcomes indicated that decitabine has a manageable toxicity profile in elderly Chinese patients. Of note, all patients enrolled in the study had de novo MDS and the majority had an ECOG score of 0 or 1 so generalizability of these results to a wider population warrants caution.

\section{CONCLUSIONS}

Decitabine, at the doses studied, was efficacious for the treatment of MDS in Chinese patients. The safety and PK profiles of decitabine were generally consistent with previous global studies in MDS, which were conducted primarily in Western populations.

\section{ACKNOWLEDGMENTS}

The authors would like to thank Ashwini Patil, MS (SIRO Clinpharm Pvt. Ltd.) for medical writing assistance, and Namit Ghildyal, PhD (Janssen Research \& Development, LLC) for additional editorial support for this manuscript. This support was funded by Xian-Janssen Pharmaceutical Ltd. China. The authors thank the study participants, without whom this study would not have been accomplished. Data from this study were presented at the 54th Annual Meeting of the
American Society of Hematology, Atlanta, GA, December 8-11, 2012. This study was funded by Xian-Janssen Pharmaceutical Ltd. China (a company of Johnson \& Johnson). The sponsor also provided formal review of manuscript. The article processing charges and open access fee for this publication were funded by Xian-Janssen Pharmaceutical Ltd. China. All named authors meet the International Committee of Medical Journal Editors (ICMJE) criteria for authorship for this manuscript, take responsibility for the integrity of the work as a whole, and have given final approval for the version to be published. All authors had access to the study data and made the final decision about where to publish these data and approved submission to this journal.

Disclosures. Hongchuang Liang is an employee of Xian-Janssen Pharmaceutical Ltd. (a company of Johnson \& Johnson). Jigang Li is an employee of Xian-Janssen Pharmaceutical Ltd. Depei Wu, Xin Du, Jie Jin, Zhijian Xiao, Zhixiang Shen, Zonghong Shao, Xiao Li, Xiaojun Huang, Ting Liu, Li Yu, Jianyong Li, Baoan Chen, Guangsheng He, Zhen Cai, and Changgeng Ruan were investigators for the study and do not have any potential conflicts of interest to declare.

Compliance with ethics guidelines. This study was conducted according to the Declaration of Helsinki, Good Clinical Practice guidelines, and other applicable regulatory requirements. The protocol was reviewed and approved by an Independent Ethics Committee at each study site and informed consent was obtained from each patient before enrollment.

Open Access. This article is distributed under the terms of the Creative Commons Attribution-NonCommercial 4.0 International 
License (http://creativecommons.org/licenses/ by-nc/4.0/), which permits any noncommercial use, distribution, and reproduction in any medium, provided you give appropriate credit to the original author(s) and the source, provide a link to the Creative Commons license, and indicate if changes were made.

\section{REFERENCES}

1. Liew E, Owen C. Familial myelodysplastic syndromes: a review of the literature. Haematologica. 2011;96:1536-42.

2. Seiter K. Myelodysplasia: new approaches. Curr Treat Options Oncol. 2013;14:156-69.

3. Cheson BD, Bennett JM, Kantarjian H, et al. Report of an international working group to standardize response criteria for myelodysplastic syndromes. Blood. 2000;96:3671-4.

4. Garcia-Manero G. Myelodysplastic syndromes: 2012 update on diagnosis, risk-stratification, and management. Am J Hematol. 2012;87:692-701.

5. Seer.cancer.gov [Internet] Survellience Research Program, NCI [updated September 10, 2014]. http://seer.cancer.gov/csr/1975_2011. Accessed 27 Sept 2014.

6. Sunnybrook.ca [Internet] Copyright (c) 2014 Sunnybrook Health Sciences Centre [updated May 2008]. http://sunnybrook.ca/uploads/Myelody splastic_Syndromes.pdf. Accessed 14 Oct 2013.

7. Chen B, Zhao WL, Jin J, et al. Clinical and cytogenetic features of 508 Chinese patients with myelodysplastic syndrome and comparison with those in Western countries. Leukemia. $2005 ; 19: 767-75$.

8. Leone G, Mele L, Pulsoni A, Equitani F, Pagano L. The incidence of secondary leukemias. Haematologica. 1999;84:937-45.

9. Klepin HD, Rao AV, Pardee TS. Acute myeloid leukemia and myelodysplastic syndromes in older adults. J Clin Oncol. 2014;32(24):2541-52.

10. List A. Methyltransferase inhibitors: changing the treatment algorithm for myelodysplastic syndromes. Cancer Control. 2004;11:16-9.

11. List AF. Treatment strategies to optimize clinical benefit in the patient with myelodysplastic syndromes. Cancer Control. 2008;15(Suppl):29-39.
12. DACOGEN ${ }^{\mathrm{TM}}$ (2010) Prescribing information. http://www.accessdata.fda.gov/drugsatfda_docs/ label/2006/021790lbl.pdf.

13. Issa JP, Garcia-Manero G, Giles FJ, et al. Phase 1 study of low-dose prolonged exposure schedules of the hypomethylating agent 5-aza-2'-deoxycytidine (decitabine) in hematopoietic malignancies. Blood. 2004;103:1635-40.

14. Kantarjian HM, O'Brien S, Cortes J, et al. Results of decitabine (5-aza-2'deoxycytidine) therapy in 130 patients with chronic myelogenous leukemia. Cancer. 2003;98:522-8.

15. Saunthararajah Y, Hillery CA, Lavelle D, et al. Effects of 5-aza-2'-deoxycytidine on fetal hemoglobin levels, red cell adhesion, and hematopoietic differentiation in patients with sickle cell disease. Blood. 2003;102:3865-70.

16. Lubbert $M$, Wijermans $P$, Kunzmann $R$, et al. Cytogenetic responses in high-risk myelodysplastic syndrome following low-dose treatment with the DNA methylation inhibitor 5-aza-2'-deoxycytidine. $\mathrm{Br} \mathrm{J}$ Haematol. 2001;114:349-57.

17. Sacchi S, Kantarjian HM, O'Brien S, et al. Chronic myelogenous leukemia in nonlymphoid blastic phase: analysis of the results of first salvage therapy with three different treatment approaches for 162 patients. Cancer. 1999;86:2632-41.

18. Willemze R, Suciu S, Archimbaud E, et al. A randomized phase II study on the effects of 5-Aza-2'-deoxycytidine combined with either amsacrine or idarubicin in patients with relapsed acute leukemia: an EORTC Leukemia Cooperative Group phase II study (06893). Leukemia. 1997;11(Suppl 1):S24-7.

19. Kantarjian H, Issa JP, Rosenfeld CS, et al. Decitabine improves patient outcomes in myelodysplastic syndromes: results of a phase III randomized study. Cancer. 2006;106:1794-803.

20. Kantarjian HM, Thomas XG, Dmoszynska A, et al. Multicenter, randomized, open-label, phase III trial of decitabine versus patient choice, with physician advice, of either supportive care or low-dose cytarabine for the treatment of older patients with newly diagnosed acute myeloid leukemia. J Clin Oncol. 2012;30:2670-7.

21. Steensma DP, Baer MR, Slack JL, et al. Multicenter study of decitabine administered daily for 5 days every 4 weeks to adults with myelodysplastic syndromes: the alternative dosing for outpatient treatment (ADOPT) trial. J Clin Oncol. 2009;27:3842-8. 
22. Kantarjian H, Oki Y, Garcia-Manero G, et al. Results of a randomized study of 3 schedules of low-dose decitabine in higher-risk myelodysplastic syndrome and chronic myelomonocytic leukemia. Blood. 2007;109:52-7.

23. Wijermans $P$, Lubbert $M$, Verhoef $G$, et al. Low-dose 5-aza-2'-deoxycytidine, a DNA hypomethylating agent, for the treatment of high-risk myelodysplastic syndrome: a multicenter phase II study in elderly patients. J Clin Oncol. 2000;18:956-62.

24. Wang XQ, Ryder J, Gross SA, Lin G, Irons RD. Prospective analysis of clinical and cytogenetic features of 435 cases of MDS diagnosed using the WHO (2001) classification: a prognostic scoring system for predicting survival in RCMD. Int J Hematol. 2009;90:361-9.

25. Matsuda A, Germing U, Jinnai I, et al. Difference in clinical features between Japanese and German patients with refractory anemia in myelodysplastic syndromes. Blood. 2005;106:2633-40.

26. Muller-Berndorff $H$, Haas PS, Kunzmann R, Schulte-Monting J, Lubbert M. Comparison of five prognostic scoring systems, the French-American-British (FAB) and World Health Organization (WHO) classifications in patients with myelodysplastic syndromes: results of a single-center analysis. Ann Hematol. 2006;85:502-13.

27. Navarro I, Ruiz MA, Cabello A, et al. Classification and scoring systems in myelodysplastic syndromes: a retrospective analysis of 311 patients. Leuk Res. 2006;30:971-7.

28. Lee JH, Jang JH, Park J, et al. A prospective multicenter observational study of decitabine treatment in Korean patients with myelodysplastic syndrome. Haematologica. 2011;96:1441-7.

29. Oki Y, Kondo Y, Yamamoto K, et al. Phase I/II study of decitabine in patients with myelodysplastic syndrome: a multi-center study in Japan. Cancer Sci. 2012;103:1839-47.

30. Blum W, Garzon R, Klisovic RB, et al. Clinical response and miR-29b predictive significance in older AML patients treated with a 10-day schedule of decitabine. Proc Natl Acad Sci USA. 2010;107:7473-8.
31. Greenberg PL, Tuechler H, Schanz J, et al. Revised international prognostic scoring system for myelodysplastic syndromes. Blood. 2012;120:2454-65.

32. Cheson BD, Greenberg PL, Bennett JM, et al. Clinical application and proposal for modification of the international working group (IWG) response criteria in myelodysplasia. Blood. 2006;108:419-25.

33. Saba HI. Decitabine in the treatment of myelodysplastic syndromes. Ther Clin Risk Manag. 2007;3:807-17.

34. Santini V. Novel therapeutic strategies: hypomethylating agents and beyond. Hematol Am Soc Hematol Educ Program. 2012;2012:65-73.

35. Qian J, Yao DM, Lin J, et al. U2AF1 mutations in Chinese patients with acute myeloid leukemia and myelodysplastic syndrome. PLoS ONE. 2012; 7:e45760.

36. Lin J, Yao DM, Qian J, et al. Recurrent DNMT3A R882 mutations in Chinese patients with acute myeloid leukemia and myelodysplastic syndrome. PLoS ONE. 2011;6:e26906.

37. Tefferi A, Vardiman JW. Myelodysplastic syndromes. N Engl J Med. 2009;361:1872-85.

38. Lee JH, Choi Y, Kim SD, et al. Comparison of 7-day azacitidine and 5-day decitabine for treating myelodysplastic syndrome. Ann Hematol. 2013;92:889-97.

39. Daskalakis M, Nguyen TT, Nguyen C, et al. Demethylation of a hypermethylated P15/INK4B gene in patients with myelodysplastic syndrome by 5-Aza-2'-deoxycytidine (decitabine) treatment. Blood. 2002;100:2957-64.

40. Valent P, Krieger O, Stauder R, et al. Iron overload in myelodysplastic syndromes (MDS)-diagnosis, management, and response criteria: a proposal of the Austrian MDS platform. Eur J Clin Invest. 2008;38:143-9.

41. CTCAE. National Institutes of Health, National Cancer Institute, Common Terminology Criteria for Adverse events. Version 3.0. 